\title{
Metamizole Use in Children: Analysis of Drug Utilisation and Adverse Drug Reactions at a German University Hospital between 2015 and 2020
}

\author{
Julia Zahn ${ }^{1}\left(\right.$ C Sonja Eberl ${ }^{1} \cdot$ Wolfgang Rödle ${ }^{2} \cdot$ Wolfgang Rascher $^{1} \cdot$ Antje Neubert $^{1} \cdot$ Irmgard Toni $^{1}$
}

Accepted: 18 October 2021 / Published online: 8 December 2021

(c) The Author(s) 2021

\begin{abstract}
Background Metamizole use is controversially discussed due to its potentially serious adverse drug reactions (ADRs). In Germany, however, it remains a popular analgesic and antipyretic drug.

Objective The aim of this study was to discuss the safety profile of metamizole in children by analysing the inpatient prescription patterns and presenting the metamizole-related ADRs at a paediatric hospital between 2015 and 2020.

Methods Metamizole utilisation data were retrospectively analysed from electronic medical records. ADRs were prospectively recorded via the hospital's stimulated reporting system and analysed accordingly. Patients aged $<18$ years admitted to one of the general wards of the department of paediatrics and adolescent medicine of a German university hospital between June 2015 and May 2020 who received at least one drug therapy within their inpatient stay were included in the analysis. Causality of ADRs was rated according to the World Health Organisation causality assessment.

Results In $31.7 \%(3759 / 11,857)$ of the inpatient stays of 7809 patients, metamizole was administered. Metamizole exposure was highest in adolescents (37.9\%) and lowest in newborns (9.9\%). Overall, metamizole was administered parenterally in about $90 \%$. Three cases of agranulocytosis, one allergic shock and one rash with possible or higher causality to metamizole treatment were reported. Three of these occurred prior to hospitalisation. All patients recovered without remaining harm.

Discussion Metamizole is commonly used in paediatric inpatients in Germany. Serious ADRs occur but rarely. Continuous monitoring of drug therapy through, for example, stimulated reporting systems ensures that serious ADRs are detected, and appropriate interventions can be introduced.
\end{abstract}

\section{Background}

Despite the controversial discussion regarding the risk-benefit ratio of metamizole (dipyrone), a non-opioid analgesic with antipyretic and antispasmodic properties, it remains a popular analgesic in Germany [1-8]. Worldwide, however, the restrictions for metamizole use differ due to its serious and potentially fatal adverse drug reactions (ADRs), such as agranulocytosis and anaphylactic reactions [9-11]. For

Julia Zahn

julia.zahn@uk-erlangen.de

1 Department of Paediatrics and Adolescent Medicine, Faculty of Medicine, Universitätsklinikum Erlangen, Friedrich-Alexander-Universität Erlangen-Nürnberg (FAU), 91054 Erlangen, Germany

2 Chair of Medical Informatics, Friedrich-Alexander-Universit ät Erlangen-Nürnberg (FAU), 91058 Erlangen, Germany example, metamizole is completely banned in the United States, the United Kingdom and the Scandinavian countries. Nevertheless, it is frequently used in Austria, Switzerland and Spain. In China and Israel, metamizole is an over-thecounter drug as it was in Germany until 1987 [9, 12-14]. Since then, Germany has restricted its use to prescriptiononly, and its licensed indications were tightened [15]. Today, metamizole is licensed for acute or chronic severe pain and high fever that does not respond to other treatments, from 3 months of age [16]. It is commonly used in both paediatric and adult patients in Germany.

Oehme et al. [17] found an increase in metamizole exposure in general paediatric medical wards in Germany from $4.7 \%$ of patients receiving medication in 1999 to $39.2 \%$ in 2008. Metamizole has also gained importance for perioperative pain treatment in paediatrics in recent years. Its use is included in guidelines on postoperative pain in Germany, Austria and on a European level [18-20]. A survey conducted in 2016 by Witschi et al. found that 68.6\% $(n=1467)$ 


\section{Key Points}

Prevalence of metamizole use for acute pain and fever management at a German paediatric hospital over five years was at around $30 \%$ of patients receiving drug therapies.

Agranulocytosis and anaphylactic shock were detected as serious but rare adverse drug reactions in association with metamizole therapy.

Stimulated reporting systems of adverse drug reactions help to identify the risks of drug therapy.

of German anaesthetists use metamizole for perioperative treatment in children $<14$ years of age [1]. However, there are no up-to-date prescription data for paediatric inpatients in Germany.

Agranulocytosis is a potentially life-threatening health condition defined by an absolute, peripheral neutrophil granulocyte count of $<500$ cells/ $\mu \mathrm{L}$ [21]. In children, various case reports of metamizole-associated agranulocytosis, including two fatal cases in adolescents, are available [22-28]. German and Swiss authorities indicated that around $4 \%$ of reported agranulocytosis or haematological ADRs associated with metamizole occurred in children, anticipating that incidence rates may be lower than in adults [2, 29, 30].

Given the increase in metamizole prescriptions between 1998 and 2008 in Germany, the lack of current inpatient prescription data and the yet unknown incidence of its (serious) ADRs in children, this analysis aims to discuss the safety profile of metamizole. This is done by analysing the inpatient prescription patterns of metamizole and presenting the metamizole-related ADRs reported via a stimulated spontaneous reporting system at the paediatric department of a large German university hospital over 5 years.

\section{Methods}

\subsection{Drug Utilisation of Metamizole at a Paediatric Hospital}

Metamizole utilisation was evaluated for the general wards (including one ward for infectious diseases) of a department of paediatrics and adolescent medicine of a German tertiary teaching hospital. We systematically reviewed the drug therapy of paediatric inpatients $<18$ years of age. For the study period 01 June 2015 to 31 May 2020, we retrospectively analysed prescription data using electronic medical records (prescription software: VMobil [31], cf. https://www.advan ova.de).
The electronic data stored in the electronic medical record VMobil were extracted, processed and compiled into a standardised Microsoft ${ }^{\circledR}$ Excel data file to analyse medication data systematically. Vitamins and food supplements were categorised with only one code; therefore, several different vitamins or food supplements in one patient cannot be distinguished in the exposure evaluation. Fluid and electrolyte infusions or parenteral nutrition were not included in this assessment. We introduced five age categories, which were adopted from the International Conference on Harmonisation ( $\mathrm{ICH}$ ) classification [32]: 0-27 days (newborns), 28 days to 23 months (infants and toddlers), 2-5 years (preschool children), 6-11 years (school children) and 12 to $<18$ years (adolescents).

In the scope of this analysis, a case is defined as an inpatient stay of a patient. If one patient was admitted to the hospital several times within the study period, all inpatient stays (cases) were included in our analysis. We retrieved data to quantify and characterise metamizole use per case (i.e. information on date of metamizole administration, route of administration, and the number of days with metamizole therapy). Descriptive patient data, age, body weight, gender, length of hospital stay and the number of different drugs per case were also collected.

In our evaluation, all cases and the subgroup of cases with any drug therapy as well as the subgroup of cases with metamizole therapy were characterised. To quantify metamizole exposure, we calculated the percentage of cases that used metamizole at least once among all included cases. Additionally, we determined the proportion of metamizole exposed cases in relation to the subgroup of cases with drug therapy.

We assessed the percentages of metamizole exposure overall, stratified by age and by study year. Descriptive results are presented with numbers, percentages or medians with interquartile range (IQR). For descriptive analysis, Microsoft ${ }^{\circledR}$ Excel and IBM ${ }^{\circledR}$ SPSS 24 were used.

\subsection{Stimulated Spontaneous Reports of Adverse Drug Reactions of Metamizole}

In 2013, an in-house quality standard for reporting ADRs and medication errors (ME) was implemented at the department of paediatrics and adolescent medicine. According to this standard, every suspected ADR and ME observed at the paediatric department is documented systematically and, irrespective of whether it led to inpatient admission or occurred during the hospital stay, reported to the Drug Commission of the German Medical Profession (Arzneimittelkommission der deutschen Ärzteschaft, Akd ̈̈) as appropriate. As the quality standard for spontaneous reporting of ADRs is subject to regular training of hospital staff as part of the hospital's quality management, the method used in the 
second part of the analysis is called a "stimulated spontaneous reporting system".

All case reports of patients $<18$ years of age recorded between 01 June 2015 and 31 May 2020 were included for our analysis. Data of the inpatient stay, including the length of hospital stay and patient demographics, such as date of birth, weight, laboratory parameters and anamnesis, were extracted from the hospital's clinical information system. Medication data, including administered drug substance, dose and route of administration, were obtained from the medical records. Age and total length of metamizole intake were calculated for each case report from the extracted variables. Continuous variables were summarised by their mean and standard deviation. The World Health Organisation-Uppsala Monitoring Centre (WHO-UMC) system was used for standardised causality assessment of suspected ADRs [33]. Causality was assessed via a consensus-based approach by a team consisting of a clinical paediatric pharmacologist and experienced pharmacists. The case reports in which causality between the ADR and metamizole was assessed as 'possible' or 'probable' are presented in detail. Data were analysed pseudonymously.

\subsection{Ethics Approval}

The local ethics committee has approved the study (Ethics Committee of the Friedrich-Alexander-Universität ErlangenNürnberg, Germany, code 561_20 Bc). Data security and privacy were ensured, and patients' identity was protected. Therefore, in accordance with the legal requirements, assent or informed consent of patients or their legal representatives was waived [34].

\section{Results}

\subsection{Drug Utilisation of Metamizole at a Paediatric Hospital}

During the study period, a total of 21,717 cases of 14,197 patients from 0 to $<18$ years of age were electronically recorded. Among those, 11,857 cases of 7809 patients received at least one drug therapy. Metamizole was administered at least once in $17.3 \%(3759 / 21,717)$ of all cases. Related to cases with drug therapy, $31.7 \%(3759 / 11,857)$ of cases involved metamizole. We observed some variability in metamizole exposure across the different years: $34.3 \%$ metamizole exposure in the first, $31.1 \%$ in the second, $35.0 \%$ in the third, $31.6 \%$ in the fourth and $26.5 \%$ in the fifth study year. Characteristics of the study population overall and of those exposed to metamizole during the inpatient stay are presented in Table 1, with results also stratified by age category. Metamizole exposure was highest in adolescents and lowest in newborns (37.9\% [1144/3019] of adolescent cases vs 9.9\% [25/252] of newborn cases with any medication). Overall, $48.8 \%$ of the patients exposed to metamizole were male. The median length of stay of cases involving metamizole administration was longer (5 days; IQR 3-8) compared with cases overall (2 days; IQR 2-5) and cases with any medication (3 days; IQR 2-6). The difference in days of hospitalisation between patients with and without metamizole was statistically significant ( $p<0.001$, all cases; $p<0.001$, cases with any medication; Mann-Whitney test). Overall, metamizole was administered parenterally in about $90 \%$ of the cases. The median number of days with metamizole therapy was 2 days (IQR 1-3). Metamizole cases received a median of 4 (IQR 2-6) different drugs.

\subsection{Stimulated Spontaneous Adverse Drug Reaction Reports of Metamizole}

Between June 2015 and May 2020, the stimulated spontaneous reporting system of the paediatric hospital resulted in seven registered case reports involving metamizole. Four of these were agranulocytosis, one allergic shock, one rash and one intoxication with suicidal character. According to the World Health Organisation (WHO) causality assessment, five cases (71.4\%) were rated to have a possible or higher causality to metamizole. The remaining two cases were one of the agranulocytosis, as this was due to cyclic neutropenia, and the suicidal intoxication with metamizole. These two cases were therefore excluded from this analysis.

Patients' baseline characteristics, information about metamizole intake and concomitant medication are displayed in Table 2. None of the reported cases ended fatally. All patients recovered without remaining harm and were discharged in good general health condition. No ME associated with metamizole was reported via the stimulated reporting system within the study period.

\subsection{Agranulocytosis}

\subsubsection{Case Report 1}

A 6-year-old boy was admitted to the paediatric hospital because of fever and a bad general health condition. The patient had taken metamizole orally $(3 \times 200 \mathrm{mg} /$ day $)$ for 14 days due to chronic pain after transtibial amputation. Amoxicillin and clavulanic acid were administered for 10 days but were already discontinued 20 days prior to admission. Sepsis in drug-induced agranulocytosis and thrombocytosis was diagnosed at admission (Table 2, Fig. 1). Intensive volume therapy was used to stabilise the circulation. Metamizole was withdrawn, and intravenous 
Table 1 Characteristics of the study population overall, with medication and exposed to metamizole, summarised by age group

\begin{tabular}{|c|c|c|c|c|c|c|c|c|}
\hline & $\begin{array}{l}\text { Number } \\
\text { of cases }^{\mathrm{d}} \\
(n)\end{array}$ & $\begin{array}{l}\text { Proportion } \\
\text { of cases } \\
\text { exposed to } \\
\text { metamizole } \\
(\%)\end{array}$ & Median age (IQR) & $\begin{array}{l}\text { Median body } \\
\text { weight }^{\mathrm{e}} \text { (IQR, kg) }\end{array}$ & $\begin{array}{l}\text { Distribu- } \\
\text { tion by } \\
\text { gender: } \\
\text { male }(\%)\end{array}$ & $\begin{array}{l}\text { Median } \\
\text { length of } \\
\text { stay (IQR, } \\
\text { days) }\end{array}$ & $\begin{array}{l}\text { Median } \\
\text { number of } \\
\text { different drugs } \\
\text { per case (IQR) }\end{array}$ & $\begin{array}{l}\text { Median } \\
\text { number of } \\
\text { days with } \\
\text { metamizole } \\
\text { therapy } \\
\text { (IQR, days) }\end{array}$ \\
\hline \multicolumn{9}{|c|}{ Total study population ( 0 to $<18$ years) } \\
\hline All inpatients ${ }^{\mathrm{a}}$ & 21,717 & 17.3 & 5.7 years $(1.8-11.9)$ & $20.5(12.3-45.3)$ & 54.5 & $2(2-5)$ & & \\
\hline $\begin{array}{l}\text { With any } \\
\text { medication }^{\mathrm{b}}\end{array}$ & 11,857 & 31.7 & 4.9 years $(1.5-12.1)$ & $20.0(12.0-44.7)$ & 50.9 & $3(2-6)$ & $3(1-5)$ & \\
\hline $\begin{array}{l}\text { Exposed to } \\
\text { metamizole }^{c}\end{array}$ & 3759 & 100 & 6.0 years $(2.0-13.3)$ & $23.5(13.4-49.9)$ & 48.8 & $5(3-8)$ & $4(2-6)$ & $2(1-3)$ \\
\hline \multicolumn{9}{|l|}{$0-27$ days } \\
\hline All inpatients ${ }^{\mathrm{a}}$ & 392 & 6.4 & 10 days (4-17) & $3.5(3.1-3.9)$ & 55.1 & $4(2-8)$ & & \\
\hline $\begin{array}{l}\text { With any } \\
\text { medication }^{\mathrm{b}}\end{array}$ & 252 & 9.9 & 11 days $(3-18)$ & $3.6(3.1-4.0)$ & 54.4 & $6(4-10)$ & $3(2-4)$ & \\
\hline $\begin{array}{l}\text { Exposed to } \\
\text { metamizole }^{c}\end{array}$ & 25 & 100 & 14 days $(1-20)$ & $3.6(3.0-4.1)$ & 64.0 & $13(7-73)$ & $7(4.5-8.5)$ & $1(1-3.5)$ \\
\hline \multicolumn{9}{|c|}{28 days to 23 months } \\
\hline All inpatients ${ }^{\mathrm{a}}$ & 5414 & 16.9 & 11.4 months $(5.6-16.9)$ & $8.4(5.7-11.0)$ & 56.3 & $3(2-5)$ & & \\
\hline $\begin{array}{l}\text { With any } \\
\text { medication }^{\mathrm{b}}\end{array}$ & 3366 & 27.2 & 10.8 months $(5.0-16.8)$ & $8.0(5.5-11.0)$ & 54.1 & $3(2-7)$ & $3(2-4)$ & \\
\hline $\begin{array}{l}\text { Exposed to } \\
\text { metamizole }^{c}\end{array}$ & 915 & 100 & 13.6 months $(8.1-18.3)$ & $10.2(6.8-11.3)$ & 53.3 & $5(3-9)$ & $4(3-6)$ & $2(1-2)$ \\
\hline \multicolumn{9}{|l|}{$2-5$ years } \\
\hline All inpatients ${ }^{\mathrm{a}}$ & 5410 & 17.3 & 3.7 years $(2.8-4.8)$ & $15.2(13.1-17.8)$ & 56.2 & $2(2-4)$ & & \\
\hline $\begin{array}{l}\text { With any } \\
\text { medication }^{\mathrm{b}}\end{array}$ & 2924 & 32.0 & 3.6 years $(2.7-4.7)$ & $15.0(13.0-17.7)$ & 53.0 & $3(2-5)$ & $3(2-5)$ & \\
\hline $\begin{array}{l}\text { Exposed to } \\
\text { metamizole }^{c}\end{array}$ & 937 & 100 & 3.6 years $(2.7-4.8)$ & $15.0(13.0-17.5)$ & 53.3 & $4(2-7)$ & $4(2-6)$ & $2(1-3)$ \\
\hline \multicolumn{9}{|l|}{$6-11$ years } \\
\hline All inpatients ${ }^{\mathrm{a}}$ & 5146 & 14.3 & 8.8 years $(7.3-10.4)$ & $28.0(22.6-35.9)$ & 58.3 & $2(1-4)$ & & \\
\hline $\begin{array}{l}\text { With any } \\
\text { medication }^{\mathrm{b}}\end{array}$ & 2296 & 32.1 & 9.0 years $(7.4-10.6)$ & $28.2(22.8-36.0)$ & 54.6 & $3(2-6)$ & $3(1-5)$ & \\
\hline $\begin{array}{l}\text { Exposed to } \\
\text { metamizole }^{c}\end{array}$ & 738 & 100 & 9.1 years $(7.6-10.6)$ & $28.0(23.0-34.9)$ & 52.6 & $4(2-9)$ & $4(2-7)$ & $2(1-3)$ \\
\hline \multicolumn{9}{|l|}{12 to $<18$ years } \\
\hline All inpatients ${ }^{\mathrm{a}}$ & 5355 & 21.4 & 15.2 years $(13.7-16.6)$ & $56.2(46.9-66.3)$ & 47.4 & $2(2-5)$ & & \\
\hline $\begin{array}{l}\text { With any } \\
\text { medication }^{\mathrm{b}}\end{array}$ & 3019 & 37.9 & 15.3 years $(13.8-16.6)$ & $56.0(46.3-66.4)$ & 42.3 & $4(2-7)$ & $3(1-5)$ & \\
\hline $\begin{array}{l}\text { Exposed to } \\
\text { metamizole }^{c}\end{array}$ & 1144 & 100 & 15.3 years $(13.7-16.5)$ & $56.5(47.1-67.3)$ & 38.7 & $5(2-9)$ & $4(2-7)$ & $2(1-3)$ \\
\hline
\end{tabular}

$I Q R$ interquartile range, $n$ number

${ }^{a}$ All inpatients: inclusion of all inpatient cases, with and without drug therapy

${ }^{b}$ With any medication: inclusion of inpatient cases with any drug therapy (parenteral nutrition or electrolyte fluids are not included)

${ }^{\mathrm{c}}$ Exposed to metamizole: inclusion of inpatient cases with metamizole therapy

${ }^{\mathrm{d}} \mathrm{A}$ case is defined as inpatient stay. Multiple hospitalisations per patient are possible

${ }^{\mathrm{e}}$ Missing values and values suspected of typos regarding the decimal place (i.e. body weight $<10 \mathrm{~kg}$ at age $>8$ months) are excluded

broad-spectrum antibiotic therapy (vancomycin, meropenem, clindamycin, cotrimoxazole) plus amphotericin B were administered for 11 days. Causality of metamizole-induced agranulocytosis was rated 'probable' as granulocytes completely regenerated spontaneously after dechallenge of metamizole, and the ADR was unlikely to be attributed to other drugs or diseases. 


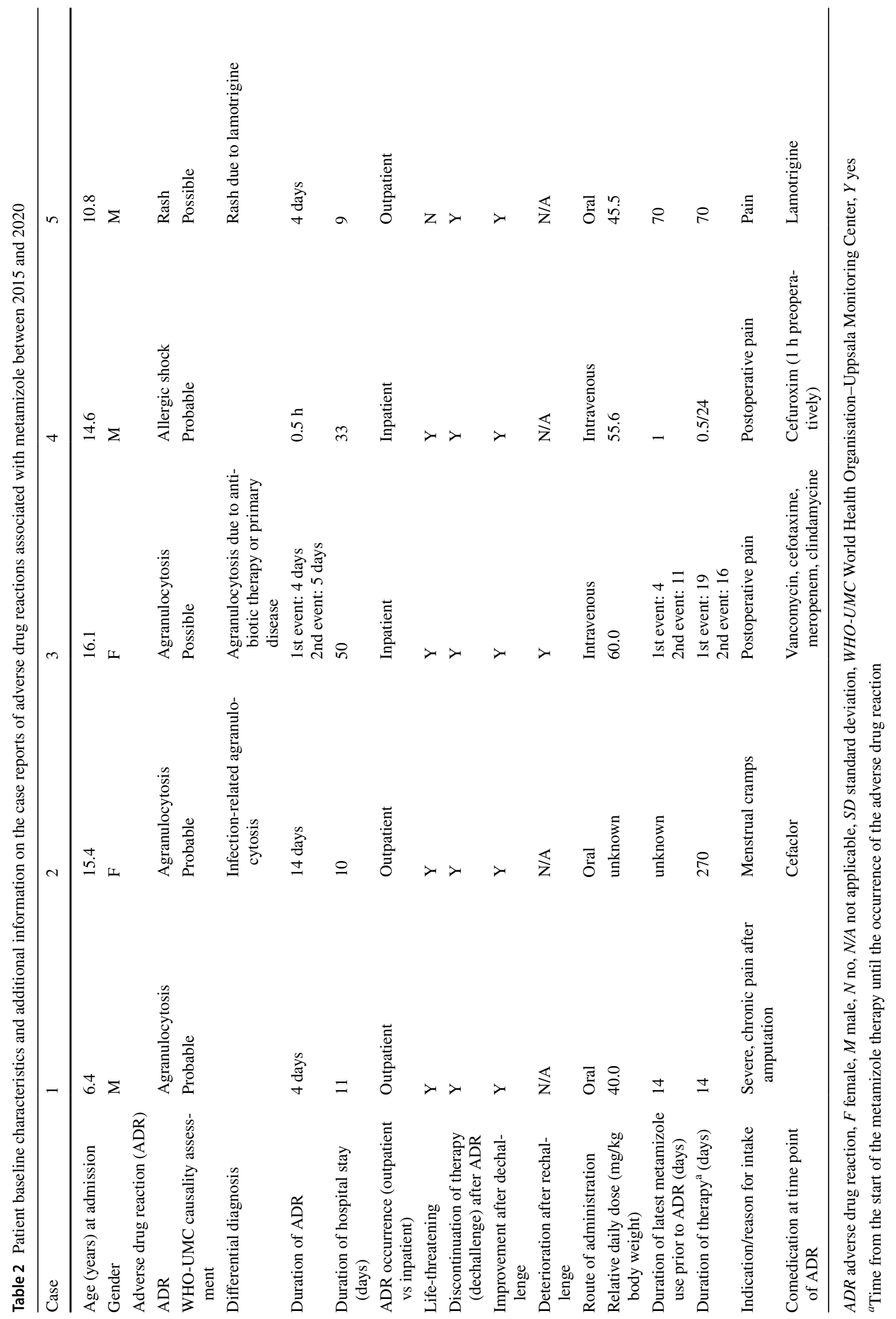




\subsubsection{Case Report 2}

A 15-year-old girl was admitted to an external hospital with fever, sore throat and fatigue. Afterwards, she was transferred to the paediatric hospital because of an intratonsillary abscess, agranulocytosis and leukocytopenia (Table 2). The patient received cefaclor $(3 \times 250 \mathrm{mg})$ and metamizole ( $3 \times$ oral drops, dose unknown) the day before hospitalisation. Anamnestically, the patient had regularly taken metamizole for menstrual cramps in the last 9 months (dose and frequency unknown). In the hospital, the abscess was surgically rehabilitated, and intravenous antibiotic therapy was initiated (initially cefotaxime, then switched to piperacillin/ tazobactam, followed by vancomycin and meropenem). For coagulopathy of unclear origin, vitamin $\mathrm{K}$ was administered once. Bone-marrow puncture showed left-shifted granulopoiesis. Complete regeneration of the peripherally measured granulocyte count was observed after 6 days (Fig. 1). The antibiotic therapy was discontinued after 10 days. Causality assessment revealed a 'probable' association between metamizole and agranulocytosis.

\subsubsection{Case Report 3}

A 16-year-old girl with pre-diagnosis of, among other things, thrombophilia with MTHFR-mutation (heterozygote) and condition after complete occlusion of the right internal jugular vein with ventriculoperitoneal (VP) shunt re-implantation was admitted because of VP shunt-associated peritonitis. Antibiotic therapy was initiated with metronidazole, vancomycin and cefotaxime. The patient received a metamizole continuous infusion $(125 \mathrm{mg} / \mathrm{h})$ for
4 days. On postoperative day 20, agranulocytosis showed up in the previously unsuspicious blood count (Fig. 2). Antibiotic therapy was changed to clindamycin and meropenem as response to the agranulocytosis. The patient received two doses $(25 \mu \mathrm{g})$ of granulocyte-colony stimulating factor (G-CSF). The antibiotic treatment was extended with metronidazole for 10 days. Metamizole (IV) was again administered for 11 days. Subsequently, agranulocytosis reoccurred. The antibiotic therapy was discontinued, and granulocytes recovered spontaneously. Neutrophils were within the normal range at blood count controls 2 and 4 months after discharge.

As various potentially agranulocytosis-associated drugs (e.g. meropenem, metronidazole and vancomycin) were administered in the temporal context of the events, additive drug-toxic effects may have led to the agranulocytosis. Causality for metamizole was therefore rated as 'possible'.

\subsection{Allergic Reactions}

\subsubsection{Case Report 4}

A 15-year-old boy with Lennox-Gastaut syndrome, MECP2 (methyl-CpG-binding-protein-2 gen) mutation and male Rett syndrome was admitted to the paediatric hospital because of poor nutritional status $(<1$ st percentile) and fatigue. At admission, no allergies were known. Due to potential dysphagia, a percutaneous endoscopic gastrostomy (PEG) was implanted without complications. The patient received metamizole continuous infusion for postoperative pain management $(2 \mathrm{~g} / 48 \mathrm{~mL}, 2 \mathrm{~mL} / \mathrm{h})$. Approximately 30 min after the start of the infusion, the patient suffered
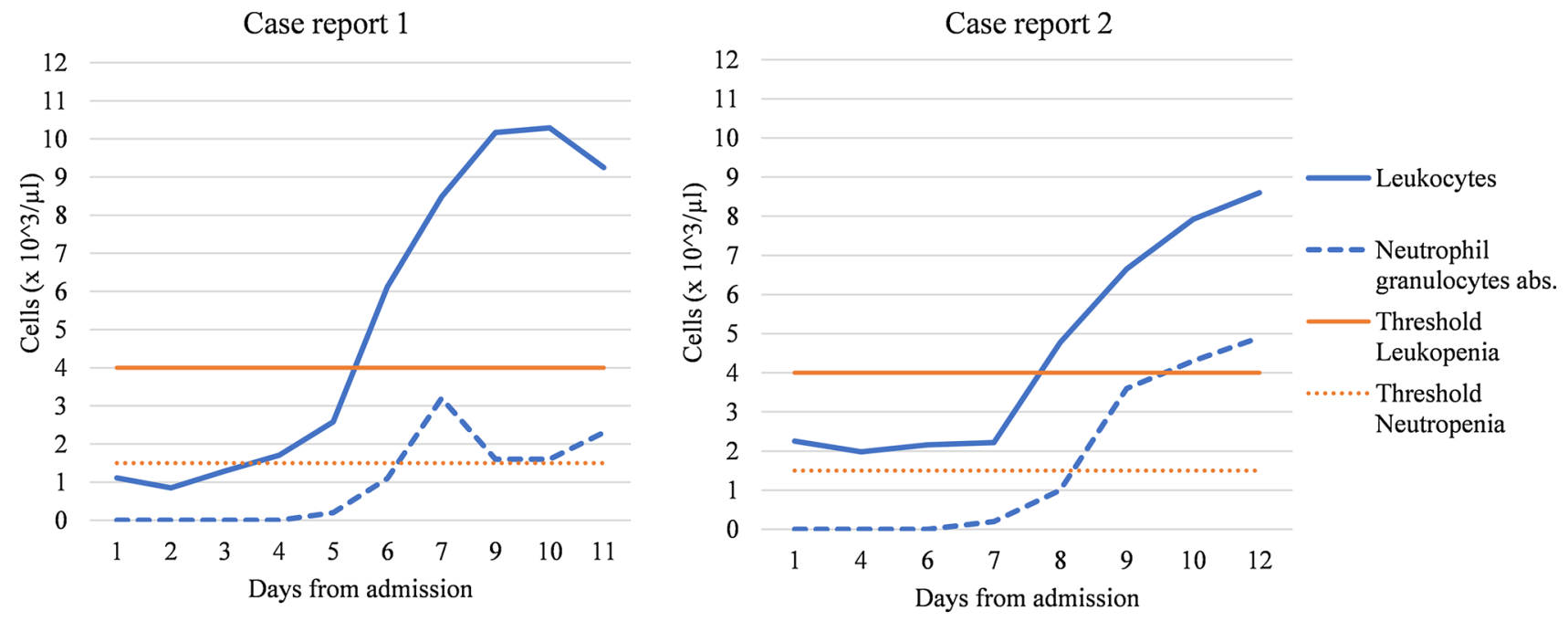

Fig. 1 Leukocytes and neutrophil granulocytes absolute $\times 10^{\wedge} 3 / \mu \mathrm{L}$ of case report 1 and case report 2 during hospital stay. Laboratory thresholds of leukopenia and neutropenia are indicated 


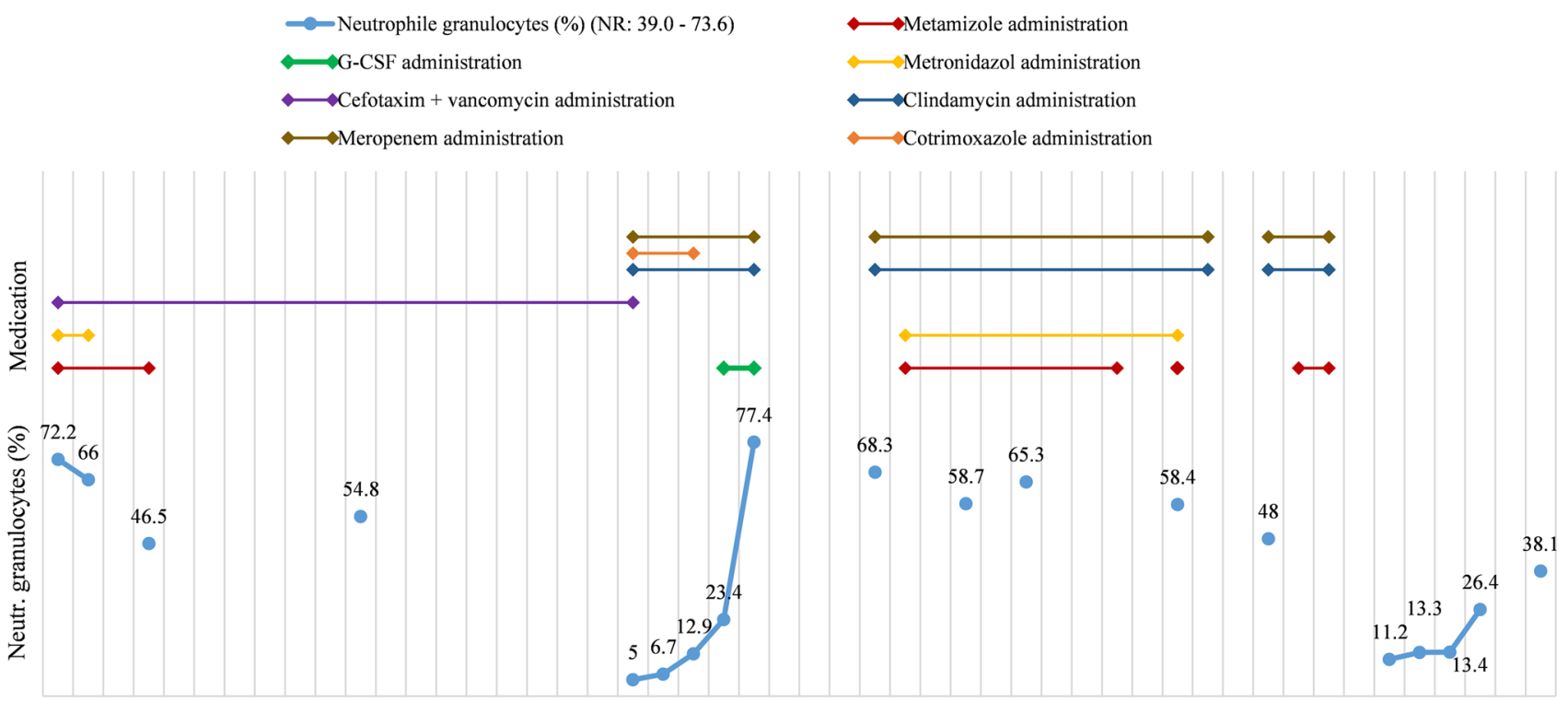

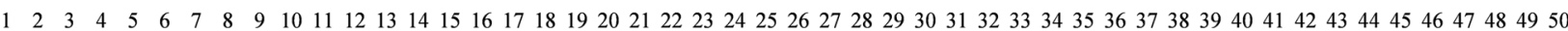
Days from admission

Fig. 2 Neutrophil granulocytes (\%) and medication in the course of the agranulocytosis of case report 3. G-CSF granulocyte-colony stimulating factor, $N R$ normal range

from a severe allergic shock with saturation declining to $67 \%$, tachydyspnoea with obstruction and whole-body urticarial rash. Metamizole infusion was stopped immediately. The patient was clinically stabilised. The rash disappeared, and the breathing pattern improved circa 30 min after discontinuation of metamizole infusion. The causality assessment revealed a 'probable' association between the allergic shock and metamizole because of the reasonable time sequence to administration and improvement of symptoms after dechallenge.

\subsubsection{Case Report 5}

A 10-year-old patient with a global developmental disorder and focal partial epilepsy was admitted to the paediatric hospital on suspicion of drug-induced rash. The patient had been on pain therapy with metamizole (500-500-500 mg) and tramadol $(0-0-50 \mathrm{mg})$ for 2 months, as well as on anticonvulsive therapy with levetiracetam $(750-0-750 \mathrm{mg}$ ) for 4 years and lamotrigine (70-0-75 mg) for 2 months. Lamotrigine was currently being titrated up (target dose: $75-0-75 \mathrm{mg}$ ). In addition to lamotrigine, metamizole was considered as a possible reason for the ADR (rash). After discontinuation of both drugs, the symptoms disappeared. The causality of metamizole was therefore classified as 'possible'.

\section{Discussion}

\subsection{Drug Utilisation of Metamizole at a Paediatric Hospital}

The analysis of the electronic medical records revealed that metamizole was administered in nearly one-third of the inpatient stays receiving medication $(3759 / 11,857)$ within a 5-year period on paediatric general wards of a large German university hospital. This proves that metamizole is commonly used and an important substance in paediatric drug therapy, even though licensed indications are restricted in Germany and its use is still prohibited in some other European countries.

Oehme et al. [17] compared the differences in drug exposure and ADRs at one of the general paediatric medical wards included in the present analysis between 1999 and 2008. One interesting finding was the general increase in prescription of analgesics and anti-inflammatory drugs between 1999 and 2008, especially paracetamol, ibuprofen and metamizole. The increase in antipyretic and analgesic medication was associated with a drop in antibiotic prescriptions [17]. To our knowledge, there are no up-to-date data describing the patterns of metamizole prescriptions in a German paediatric hospital. Therefore, one of the main questions motivating this work was whether metamizole inpatient prescription patterns in children and adolescents 
have changed since 2008. Our study revealed slightly lower metamizole prescription rates compared with the 2008 data by Oehme et al. (39.2\% [2008] vs 31.7\% [2015-2020]). However, differences in the patient cohorts of the two studies need to be taken into account. The 2008 cohort only included data from one ward with the main focus on infectious disease, where more antipyretic medication is usually required. In the present study, various general paediatric wards were included besides the infectious disease ward, such as those with a focus on neuropaediatric diseases. The median age (5.0 years [2008] vs 4.9 years [2015-2020]), as well as the number of prescribed drugs per patient/case (3 drugs, each), was similar for both cohorts [17]. In our study, the use of metamizole fluctuated from year to year in the 5-year observation period but remained in the 26-35\% range in patients receiving medication during their inpatient stay. In the last observation year (06/2019-05/2020), there was a decrease in metamizole exposure and the number of hospitalised patients. This might be explained by the fact that the first lockdown of the coronavirus pandemic was imposed in March 2020. It has already been shown that the lockdown has led to a decrease in paediatric hospitalisation, in part due to a decline in communicable infectious diseases or cancellation of planned procedures [35]. For a more detailed investigation of a possible trend, indications and the use of alternative therapy options would have to be considered. However, given these comparisons, it can be assumed that there has been no significant increase in metamizole exposure in paediatric inpatients since 2008, as has been reported for the adult population in Germany [8].

In 2016, a survey by Witschi et al. [1] found that $68.6 \%$ of anaesthetists ( $n=1467)$ use metamizole for perioperative, and $36.9 \%$ for postoperative pain treatment in children $<14$ years of age. Intraoperatively, metamizole was used significantly more often compared with paracetamol and other NSAIDs [1]. These numbers once more prove the high relevance given to metamizole in paediatrics in Germany. Besides its excellent analgesic and antipyretic efficacy, other reasons for the high metamizole use may be its low organ toxicity, therapeutic index, few contraindications, low costs, and, especially for Germany, the possible reimbursement by health insurance companies [1, 8, 36, 37]. Another argument for metamizole use may be the reduction of opioid use after trauma surgery, which is, however, more important in the adult population [38].

Rashed et al. [39] showed that metamizole was the second most prescribed drug after ibuprofen in Germany. Reasons for that may be the lack of alternatives. The intravenous ibuprofen formulation was only recently licensed for patients aged from 6 years for symptomatic short-term treatment of acute moderate pain and fever when intravenous use is clinically justified and other routes of administration are not possible [40]. Previously, intravenous ibuprofen was only licensed for ductus arteriosus occlusion in premature infants [41], but was already used off-label as an intravenous analgesic and antipyretic drug in younger patients [42]. Although intravenous paracetamol formulations are available and licensed for short-term treatment of moderate pain and fever [43], there are concerns about its hepatotoxicity [44]. Metamizole is available as intravenous formulations and is licensed from the age of 3 months [45], which may be reasons for its popularity as a non-opioid analgesic in Germany.

Our data demonstrated that patients receiving metamizole had a statistically significant longer median length of stay than other patients. This could be partly explained by the severity of the illness of patients receiving metamizole therapy or the association with a prolonged length of stay due to a surgical procedure. However, our data also showed that the median number of days with metamizole therapy was only 2 days overall. We did not evaluate the indications in which metamizole was administered. Nevertheless, the low number of days with metamizole therapy and the high amount of parenteral use support our assumption that metamizole was only used short term and within the scope of its licence. In addition, a meta-analysis on metamizole-associated ADRs in adults concluded that short-term metamizole use in the hospital setting seems to be safe [9]. Except for the allergic shock, in our analysis all patients with a metamizoleassociated ADR had started metamizole therapy at least 14 days prior to the event. This supports the hypothesis that long-term use should be considered critically. Further studies are needed evaluating the prolonged use of metamizole.

\subsection{Safety Assessment of Metamizole}

\subsubsection{Stimulated Spontaneous Reports of Adverse Drug Reactions of Metamizole}

Within the 5-year reporting period of this study, five ADRs related to metamizole were identified by the hospital's stimulated spontaneous reporting system. Only two of these ADRs occurred during inpatient treatment. In the other cases, patients had taken metamizole in an outpatient setting and were consequently hospitalised due to the ADR.

Oehme et al. discovered that metamizole was not significantly associated with ADRs during 8 months in 1999/2000 and 3 months in 2008. Nevertheless, the authors concluded that metamizole use is safe and effective when used properly and suggested the establishment of a prospective pharmacovigilance system to improve medication safety in paediatrics [17].

Our study used a prospective approach by stimulated spontaneous reporting of ADRs, which is qualified to serve as an in-house pharmacovigilance system. Although chart review is considered the gold standard for obtaining data 
on the incidence of ADRs [46], the risk is considered low that severe ADRs were missed during our study period. The reason for the latter is that our analysis started more than 1 year after implementing the hospital's reporting system. Therefore, reliable reporting processes were established and strengthened by regular training of hospital staff.

\subsubsection{Agranulocytosis}

Metamizole is known to have myelotoxic characteristics and can therefore cause agranulocytosis. Agranulocytosis is a potentially life-threatening health condition. Fever, throat pain and tonsillitis are clear signs of agranulocytosis. In case of exacerbation, bacterial superinfections and tonsil abscesses requiring surgery may also occur, which have been observed in our patients with agranulocytosis [21, 47].

Reported incidence rates of metamizole-induced agranulocytosis (MIA) in adults are heterogeneous, ranging from one per million [48, 49] up to one per 1439 patients [50-53]. The latter is the only study to our knowledge that shows such high incidence rates. Very little was found in the literature regarding the incidence of MIA in children and adolescents. By evaluating retrospective analysis of spontaneous reports to the national authorities in Switzerland and Germany, lower incidence rates compared with adults (referred to as one case per million or one per two million) were anticipated [2, 22, 23, 29]. Stammschulte et al. revealed that "older age is probably a risk factor for severe complications and fatal outcome" when they analysed the German spontaneous reports between 1990 and 2012 with patients aged 11-85 years. The authors, however, also remarked that severe ADRs occurred in all age groups [29].

A post-authorisation safety study from 2015 did not find any drug-induced agranulocytosis after a single parenteral dose of metamizole for post-operative treatment in 1177 children aged up to 6 years [36]. This aligns with our study, where no ADRs were identified in children under 6 years of age and with short-term administration. Nevertheless, it must be critically emphasised that the sample size, follow-up and identification of agranulocytosis in the aforementioned post-authorisation safety study were insufficient to detect all agranulocytosis episodes [10, 53]. Possible reasons are, for example, that agranulocytosis can occur more than 28 days after intake [53], and a reduction of neutrophil granulocytes can also occur without any clinical signs like infection [54]. Therefore, further investigations are needed focussing on ADR detection after metamizole use.

Furthermore, besides metamizole, other drugs may have myelotoxic properties, such as clozapine, sulfasalazine, thiamazole, and carbamazepine [55]. Concomitant use can potentiate myelotoxic effects. In case report 3 of the spontaneous reports, it was difficult to find the causative drug, as the patient received several agranulocytosis-associated drugs. However, looking at the drug administration over time in retrospect, it seems obvious that metamizole played a role (Fig. 2). Also, it is possible that the second agranulocytosis could have been prevented if metamizole had not been used again. Therefore, it is essential for every physician to be aware of the potential side effects, to examine the medication for risks and to adjust it if necessary.

\subsubsection{Allergic Reactions}

Metamizole is known to potentially cause severe allergic reactions, especially when being administered parenterally. The summary of product characteristics (SmPC) of Novalgin ${ }^{\circledR}$ solution for infusion states that parenteral drug administration is associated with a higher risk of anaphylactic or anaphylactoid reactions in total. However, these reactions are reported as rare events [16]. Within the reporting period, there was one patient with an anaphylactic shock after intravenous application of metamizole. The patient recovered completely due to the promptly implemented interventions. Our study revealed that most metamizole administrations (around 90\%) were given parenterally, similar to what was found in 2008 [56]. Also, the high proportion of parenteral administration reflects that metamizole is mainly used for severe pain and in patients requiring intravenous therapy.

\subsubsection{International Safety Assessments by Authorities}

In 2019, metamizole use had undergone a referral by the Committee for Medicinal Products for Human Use (CHMP) due to noted divergences in the product information of metamizole-containing medicinal products across EU member states. In its scientific evaluation, the Committee concluded that the risk-benefit balance of metamizole-containing medicinal products remains unchanged. For children up to 14 years of age, the Committee recommends doses as actually stated in the German SmPC (8-16 mg/kg body weight as a single dose up to 4 times daily at intervals of 6-8 h). Further, the CHMP highlighted that no particular concerns arose from the studies that included patients $<3$ months old $[36,37]$. Therefore, there is no reason to generally reject the administration of metamizole below the age of 3 months [57].

Only recently, a debate emerged on another ADR of metamizole. In 2020, the Pharmacovigilance Risk Assessment Committee (PRAC) published their scientific conclusions about a causal relationship between metamizole and druginduced liver injury based on available literature. As a result, the PRAC called for the addition of a warning in the product information and released a Direct Healthcare Professional Communication letter (DHPC) about this ADR [58]. In our study, no case report was found with regard to drug-induced 
liver injury. In the future, however, the metamizole-induced liver injury needs to be investigated in paediatric inpatients to find out more about this particular risk in minors.

\subsection{Strengths and Limitations}

To our knowledge, this is the first study evaluating metamizole drug utilisation in combination with stimulated spontaneous reporting system data in paediatric inpatients. As drug utilisation from the same hospital was already published for 1999 and 2008, we could compare metamizole exposure between the studies directly. Drug utilisation data were automatically extracted from the electronic medical records, avoiding errors due to manual transcriptions. In addition, our methodology only included the doses that were actually administered. Especially in the case of on-demand medication such as analgesics, a considerable difference can occur between the doses prescribed and those actually administered.

Our data do not reflect the picture of all inpatients, as not all wards could be included in the analysis. This is because the electronic medical record from which the prescription data were extracted was only used on general paediatric wards. Therefore, oncology, surgical or intensive care patients were not included, and no conclusions can be drawn about the frequency of metamizole use on these wards. Moreover, our data only allowed the evaluation of metamizole exposure, but not a precise characterisation of clinical use by indication and dosage. However, from clinical experience, we know that metamizole is mainly used for short-term therapy following the hospital's standard operating procedures (SOPs), such as for 'postoperative pain', 'care after PEG placement' and 'first aid for scald and burn'. In these SOPs, the dosage information is as follows: single doses of $10-15 \mathrm{mg} / \mathrm{kg}$, maximum $60 \mathrm{mg} / \mathrm{kg}$ per day [59]. Ziesenitz et al. showed that infants $<1$ year of age need lower metamizole doses $(5 \mathrm{mg} / \mathrm{kg})$ to achieve equivalent adult exposure [60].

To date, there are only a few studies combining drug utilisation with stimulated reporting system data, as we did. By doing so, the individual drug risk can only be estimated on a population level but not on an individual level. Also, combining these sources for risk estimates, one has to be very cautious as the data come from different databases and may be biased. In the present study, it is hardly possible to define the population at risk, as we only analysed the inpatient data. As agranulocytosis can appear more than 28 days after metamizole intake [53], it could be the case that the patient has already been discharged, especially when taking into account the median length of hospital stay of 3 days (IQR 2-6) in our study. Moreover, three of our patients had taken metamizole in the ambulatory setting and are therefore not included in the utilisation data. For these reasons, calculating the reporting rate or the incidence is not possible from our point of view.

\section{Conclusion}

This study shows that metamizole use in paediatric inpatients is common in Germany; the exposure was at around $30 \%$ of paediatric inpatients receiving medication on general paediatric medical wards over a 5 -year period. Few but potentially life-threatening ADRs (e.g. agranulocytosis and anaphylactic shock) were identified in association with metamizole. In three of five identified ADRs, patients had received metamizole in the ambulatory setting for at least 14 days. This highlights the risks associated with metamizole if used for a longer period and outside the licensed indications.

Overall, however, the results of this study seem to suggest that metamizole is a safe analgesic and antipyretic drug if used for short-term periods. Nevertheless, awareness of physicians and ward staff towards possible complications is essential.

Stimulated hospital ADR reporting systems are an effective measure to monitor pharmacotherapy and improve patient safety. They must continue to be promoted and trained among health professionals.

Acknowledgements The present work was performed in partial fulfillment of the requirements for obtaining the degree "Dr. rer. biol. hum." of the Friedrich-Alexander-Universität of Erlangen-Nurnberg (FAU) (JZ).

Author Contributions Conceptualisation: Antje Neubert (AN), Irmgard Toni (IT), Wolfgang Rascher (WR), Sonja Eberl (SE), Julia Zahn (JZ); methodology: AN, IT, WR, SE, JZ; data collection: IT, SE, Wolfgang Rödle (WRö), JZ; Software (drug utilisation): programming: WRö; export and curation of data: WRö, SE; data curation and validation (drug utilisation): SE, WRö and JZ; data analysis and interpretation (drug utilisation): JZ, SE, IT, data curation (adverse drug reactions): JZ; data analysis and interpretation (adverse drug reactions): JZ, WR, IT; writing-original draft preparation: JZ; writing—review and editing: all authors; final approval of the version to be published: all authors.

\section{Declarations}

Funding Open Access funding enabled and organized by Projekt DEAL. This research did not receive any external funding.

Conflict of Interest The authors declare that there is no conflict of interest.

Ethics Approval The local ethics committee has approved the study (Ethics Committee of the Friedrich-Alexander-Universität ErlangenNürnberg, Germany, code 561_20 Bc). The study was performed in accordance with the ethical standards as laid down in the 1964 Declaration of Helsinki and its later amendments. 
Consent to Participate Not applicable.

Consent for Publication Not applicable.

Availability of Data and Material (Data Transparency) Data are available on reasonable request from the authors.

Code Availability (Software Application or Custom Code) Not applicable.

Open Access This article is licensed under a Creative Commons Attribution-NonCommercial 4.0 International License, which permits any non-commercial use, sharing, adaptation, distribution and reproduction in any medium or format, as long as you give appropriate credit to the original author(s) and the source, provide a link to the Creative Commons licence, and indicate if changes were made. The images or other third party material in this article are included in the article's Creative Commons licence, unless indicated otherwise in a credit line to the material. If material is not included in the article's Creative Commons licence and your intended use is not permitted by statutory regulation or exceeds the permitted use, you will need to obtain permission directly from the copyright holder. To view a copy of this licence, visit http://creativecommons.org/licenses/by-nc/4.0/.

\section{References}

1. Witschi L, Reist L, Stammschulte T, Erlenwein J, Becke K, Stamer U. Perioperative use of metamizole and other nonopioid analgesics in children: results of a survey. Anaesthesist. 2019;68(3):15260. https://doi.org/10.1007/s00101-018-0532-4.

2. Blaser LS, Tramonti A, Egger P, Haschke M, Krahenbuhl S, Ratz Bravo AE. Hematological safety of metamizole: retrospective analysis of WHO and Swiss spontaneous safety reports. Eur J Clin Pharmacol. 2015;71(2):209-17. https://doi.org/10.1007/ s00228-014-1781-z.

3. Hoffmann F, Meinecke P, Freitag MH, Glaeske G, Schulze J, Schmiemann G. Who gets dipyrone (metamizole) in Germany? Prescribing by age, sex and region. J Clin Pharm Ther. 2015;40(3):285-8. https://doi.org/10.1111/jcpt.12261.

4. Klose S, Pflock R, König IR, Linder R, Schwaninger M. Metamizole and the risk of drug-induced agranulocytosis and neutropenia in statutory health insurance data. Naunyn Schmiedebergs Arch Pharmacol. 2020;393(4):681-90. https://doi.org/10.1007/ s00210-019-01774-4.

5. Vizdiklar C, Akici N, Aydin V, Donertas B, Alkan A, Akici A. Evaluation of injectable metamizole utilization in children and adults in primary care. Int $\mathrm{J}$ Clin Pharmacol Ther. 2020;58(12):718-26. https://doi.org/10.5414/cp203815.

6. de Leeuw TG, de Wildt SN. Reply to Stamer, Ulrike; Stüber, Frank, regarding their comment 'Analgesic efficacy of dipyrone children-still an absence of evidence.' Paediatr Anaesth. 2018;28(12):1156. https://doi.org/10.1111/pan.13484.

7. de Leeuw TG, Dirckx M, de Wildt SN. Reply to Ziesenitz, Victoria; Erb Thomas; Trachsel, Daniel; van den Anker Johannes, regarding their comment "Safety of dipyrone (metamizole) in children-what's the risk of agranulocytosis?" Paediatr Anaesth. 2018;28(3):305-6. https://doi.org/10.1111/pan.13326.

8. Schwabe U, Ludwig W-D. Arzneiverordnungsreport 2020. Heidelberg: Springer; 2020.

9. Kotter T, da Costa BR, Fassler M, Blozik E, Linde K, Juni P, Reichenbach S, Scherer M. Metamizole-associated adverse events: a systematic review and meta-analysis. PLoS One. 2015. https:// doi.org/10.1371/journal.pone.0122918.
10. Rollason V, Desmeules JA. Use of metamizole in children and the risk of agranulocytosis: is the benefit worth the risk? Eur J Anaesthesiol. 2015;32(12):837-8. https://doi.org/10.1097/EJA. 0000000000000275.

11. Gladtke E. Use of antipyretic analgesics in the pediatric patient. Am J Med. 1983;75(5A):121-6. https://doi.org/10.1016/00029343(83)90243-7.

12. Bhaumik S. India's health ministry bans pioglitazone, metamizole, and flupentixol-melitracen. BMJ. 2013;347: f4366. https://doi.org/ 10.1136/bmj.f4366.

13. de Leeuw TG, Dirckx M, Gonzalez Candel A, Scoones GP, Huygen F, de Wildt SN. The use of dipyrone (metamizol) as an analgesic in children: what is the evidence? A review. Paediatr Anaesth. 2018;28(3):309. https://doi.org/10.1111/pan.13341.

14. Hoffmann F, Bantel C, Jobski K. Agranulocytosis attributed to metamizole: an analysis of spontaneous reports in EudraVigilance 1985-2017. Basic Clin Pharmacol Toxicol. 2020;126(2):116-25. https://doi.org/10.1111/bcpt.13310.

15. Arzneimittelkommission der deutschen Ärzteschaft. „Aus der UAW-Datenbank" Agranulozytose nach Metamizol - sehr selten, aber häufiger als gedacht. Dtsch Arztebl. 2011;108(33):1758-9.

16. Sanofi-Aventis Deutschland GmbH. SmPC Novalgin ${ }^{\circledR}$ Tropfen 500 mg/ml, Tropfen zum Einnehmen, Lösung. 03/2017.

17. Oehme AK, Rashed AN, Hefele B, Wong IC, Rascher W, Neubert A. Adverse drug reactions in hospitalised children in Germany are decreasing: results of a nine year cohort-based comparison. PLoS One. 2012. https://doi.org/10.1371/journal.pone.0044349.

18. Messerer B, Grogl G, Stromer W, Jaksch W. Pediatric perioperative systemic pain therapy: Austrian interdisciplinary recommendations on pediatric perioperative pain management. Schmerz. 2014;28(1):43-64. https://doi.org/10.1007/s00482-013-1384-0.

19. Reuß MF, Schramm C. Grundzüge des perioperativen Schmerzmanagements bei Säuglingen, Kindern und Jugendlichen. Monatsschr Kinderheilkd. 2020;168(12):1108-17. https://doi. org/10.1007/s00112-020-01045-0.

20. Vittinghoff M, Lonnqvist PA, Mossetti V, Heschl S, Simic D, Colovic V, Dmytriiev D, Holzle M, Zielinska M, Kubica-Cielinska A, et al. Postoperative pain management in children: guidance from the pain committee of the European Society for Paediatric Anaesthesiology (ESPA Pain Management Ladder Initiative). Paediatr Anaesth. 2018;28(6):493-506. https://doi.org/10.1111/ pan.13373.

21. Johnston A, Uetrecht J. Current understanding of the mechanisms of idiosyncratic drug-induced agranulocytosis. Expert Opin Drug Metab Toxicol. 2015;11(2):243-57. https://doi.org/10.1517/17425 255.2015.985649.

22. Kilic O, Iseri Nepesov M, Ulukapi HB, Ozdemir ZC, Bor O, Dinleyici EC. Paediatric agranulocytosis associated with metamizole treatment. Paediatr Drugs. 2021;23(1):105-10. https://doi.org/10. 1007/s40272-020-00431-1.

23. Bonkowsky JL, Frazer JK, Buchi KF, Byington CL. Metamizole use by Latino immigrants: a common and potentially harmful home remedy. Pediatrics. 2002;109(6): e98. https://doi.org/10. 1542/peds.109.6.e98.

24. Isik M, Kaya Z, Belen FB, Aktas AT, Tezer H, Gursel T. Lifethreatening agranulocytosis, anemia, and plasmacytosis after dipyrone use for fever in a child. J Pediatr Hematol Oncol. 2014;36(1):e46-48. https://doi.org/10.1097/MPH.0b013e3182 $6 \mathrm{e} 7 \mathrm{~d} 9 \mathrm{~d}$.

25. Pfersdorff M, Spes J, Kraus MR. 17-year-old patient with neutropenia and fever during therapy with analgesics. Dtsch Med Wochenschr. 2011;136(8):365-8. https://doi.org/10.1055/s-00311272537.

26. Wurl W, Stadelmann I, Rudolph C, Hüseman D. Jugendlicher mit Kopfschmerzen und Agranulozytose. Monatsschr Kinderheilkd. 2020;168(8):674-8. https://doi.org/10.1007/s00112-020-00963-3. 
27. Aslan N, Yildizdas D, Horoz OO, Ozden O. Fatal agranulocytosis and Fournier's gangrene due to the use of metamizole. Indian J Pediatr. 2019;86(3):310-1. https://doi.org/10.1007/ s12098-018-2799-5.

28. Magloire PS, Mamady D, Pascal M, Gustave KK. Fatal agranulocytosis associated with Metamizole treatment in a 16-year-old girl. Blood. 2019;30(50):100.

29. Stammschulte T, Ludwig WD, Muhlbauer B, Bronder E, Gundert-Remy U. Metamizole (dipyrone)-associated agranulocytosis. An analysis of German spontaneous reports 1990-2012. Eur J Clin Pharmacol. 2015;71(9):1129-38. https://doi.org/10.1007/ s00228-015-1895-y.

30. Jaffan L, Laer S. Adverse drug reactions in children. Ther Umsch. 2011;68(1):34-40. https://doi.org/10.1024/0040-5930/a000117.

31. Bleisinger B, Hartmann P, Schels T. Elektronische Patientenkurve. Schluss mit Notizzetteln. Dtsch Arztebl. International. 2013;110(14):12-1

32. International Conference on Harmonisation of Technical Requirements for Registration of Pharmaceuticals for Human Use. ICH Harmonised Tripartite Guideline. Clinical investigation of medicinal products in the pediatric population E11 Step 4. 2000.

33. Uppsala Monitoring Centre. The use of the WHO-UMC system for standardized case causality assessment. http://who-umc.org/ Graphics/24734.pdf. Accessed 04 Nov 2021.

34. Bayerisches Krankenhausgesetz (BayKrG) in der Fassung der Bekanntmachung vom 28. März 2007 zuletzt geändert am 13. Dezember 2016 (GVB1, S. 288).

35. Kruizinga MD, Peeters $\mathrm{D}$, van Veen $\mathrm{M}$, van Houten $\mathrm{M}$, Wieringa J, Noordzij JG, Bekhof J, Tramper-Stranders G, Vet NJ, Driessen GJA. The impact of lockdown on pediatric ED visits and hospital admissions during the COVID19 pandemic: a multicenter analysis and review of the literature. Eur J Pediatr. 2021;180(7):2271-9. https://doi.org/10.1007/s00431-021-04015-0.

36. Fieler M, Eich C, Becke K, Badelt G, Leimkühler K, Messroghli L, Boethig D, Sümpelmann R. Metamizole for postoperative pain therapy in 1177 children: a prospective, multicentre, observational, postauthorisation safety study. Eur J Anaesthesiol. 2015;32(12):839_ 43. https://doi.org/10.1097/eja.0000000000000272.

37. Sümpelmann R, Fieler M, Eich C, Becke K, Badelt G, Leimkühler $\mathrm{K}$, Dennhardt N. Metamizole for postoperative pain therapy in infants younger than 1 year. Eur J Pediatr Surg. 2017;27(3):26973. https://doi.org/10.1055/s-0036-1587332.

38. Steffen P, Krinn E, Möller A, Seeling W, Rockemann MG. Metamizol and diclofenac profoundly reduce opioid consumption after minor trauma surgery. Acute Pain. 2002;4(2):71-5.

39. Rashed AN, Wong IC, Wilton L, Tomlin S, Neubert A. Drug utilisation patterns in children admitted to a paediatric general medical ward in five countries. Drugs Real World Outcomes. 2015;2(4):397-410. https://doi.org/10.1007/s40801-015-0049-y.

40. B. Braun Melsungen AG. SmPC Ibuprofen B. Braun $200 \mathrm{mg}$ Infusionslösung. 03/2021.

41. Recordati Rare Diseases. SmPC Pedea $5 \mathrm{mg} / \mathrm{ml}$ Injektionslösung. 04/2019.

42. Anderson BJ, Hannam JA. A target concentration strategy to determine ibuprofen dosing in children. Pediatr Anesth. 2019;29(11):1107-13.

43. B. Braun Melsungen AG. SmPC Paracetamol B. Braun $10 \mathrm{mg} / \mathrm{ml}$ Infusionslösung. 09/2019.

44. Brune K, Renner B, Tiegs G. Acetaminophen/paracetamol: a history of errors, failures and false decisions. Eur J Pain. 2015;19(7):953-65. https://doi.org/10.1002/ejp.621.

45. Sanofi-Aventis Deutschland GmbH. SmPC Novalgin ${ }^{\circledR} 1$ g-Injektionslösung, Novalgin ${ }^{\circledR} 2,5$ g-Injektionslösung. 01/2021.

46. Manias E. Detection of medication-related problems in hospital practice: a review. Br J Clin Pharmacol. 2013;76(1):7-20. https:// doi.org/10.1111/bcp.12049.
47. Garbe E. Non-chemotherapy drug-induced agranulocytosis. Expert Opin Drug Saf. 2007;6(3):323-35. https://doi.org/10.1517/ 14740338.6.3.323.

48. IAAAS Study Group. Risks of agranulocytosis and aplastic anemia. A first report of their relation to drug use with special reference to analgesics. The International Agranulocytosis and Aplastic Anemia Study. JAMA. 1986;256(13):1749-57.

49. Huber M, Andersohn F, Sarganas G, Bronder E, Klimpel A, Thomae M, Konzen C, Kreutz R, Garbe E. Metamizole-induced agranulocytosis revisited: results from the prospective Berlin Case-Control Surveillance Study. Eur J Clin Pharmacol. 2015;71(2):219-27. https://doi.org/10.1007/s00228-014-1777-8.

50. Basak GW, Drozd-Sokołowska J, Wiktor-Jedrzejczak W. Update on the incidence of metamizole sodium-induced blood dyscrasias in Poland. J Int Med Res. 2010;38(4):1374-80. https://doi.org/10. $1177 / 147323001003800419$.

51. van der Klauw MM, Goudsmit R, Halie MR, van't Veer MB, Herings RM, Wilson JH, Stricker BH. A population-based casecohort study of drug-associated agranulocytosis. Arch Intern Med. 1999;159(4):369-74. https://doi.org/10.1001/archinte.159.4.369.

52. Ziesenitz VC, Erb TO, Trachsel D, van den Anker JN. Safety of dipyrone (metamizole) in children-what's the risk of agranulocytosis? Paediatr Anaesth. 2018;28(2):186-7. https://doi.org/10. 1111/pan.13312.

53. Hedenmalm K, Spigset O. Agranulocytosis and other blood dyscrasias associated with dipyrone (metamizole). Eur J Clin Pharmacol. 2002;58(4):265-74. https://doi.org/10.1007/ s00228-002-0465-2.

54. Tajiri J, Noguchi S. Antithyroid drug-induced agranulocytosis: special reference to normal white blood cell count agranulocytosis. Thyroid. 2004;14(6):459-62. https://doi.org/10.1089/10507 2504323150787.

55. Huber M, Andersohn F, Bronder E, Klimpel A, Thomae M, Konzen C, Meyer O, Salama A, Schrezenmeier H, Hildebrandt $\mathrm{M}$, et al. Drug-induced agranulocytosis in the Berlin case-control surveillance study. Eur J Clin Pharmacol. 2014;70(3):339-45. https://doi.org/10.1007/s00228-013-1618-1.

56. Botzenhardt S, Rashed AN, Wong IC, Tomlin S, Neubert A. Analgesic drug prescription patterns on five international paediatric wards. Paediatr Drugs. 2016;18(6):465-73. https://doi.org/10. 1007/s40272-016-0198-9.

57. European Medicines Agency, Committee on Medicinal Products for Human Use (CHMP). Assessment report. Referral under Article 31 of Directive 2001/83/EC. EMA/143912/2019. Metamizole Article 31 Referral Annex II. Scientific Conclusions. 2019.

58. European Medicines Agency, Pharmacovigilance Risk Assessment Committee (PRAC). Metamizole: CMDh Scientific conclusions and grounds for the variation to the terms of the Marketing Authorisation(s): Metamizole. Procedure number: PSUSA/00001997/202003. Last update: 18/12/2020. https://www. ema.europa.eu/en/documents/psusa/metamizole-cmdh-scientificconclusions-grounds-variation-amendments-product-informationtimetable/00001997/202003_de.pdf. Accessed 04 Nov 2021.

59. Böswald W, Grießinger N. Postoperative Schmerztherapie bei Kindern. UKER-8-14761. QM-System UKER, Standard Operating Procedure (SOP), 2017.

60. Ziesenitz VC, Rodieux F, Atkinson A, Borter C, Bielicki JA, Haschke M, Duthaler U, Bachmann F, Erb TO, Gürtler N, et al. Dose evaluation of intravenous metamizole (dipyrone) in infants and children: a prospective population pharmacokinetic study. Eur J Clin Pharmacol. 2019;75(11):1491-502. https://doi.org/10.1007/ s00228-019-02720-2. 